BMJ Paediatrics Open

\title{
Anaphylaxis management: a survey of school and day care nurses in Lebanon
}

Tamar Avedissian, ${ }^{1}$ Gladys Honein-AbouHaidar, ${ }^{1}$ Nuhad Dumit, ${ }^{1,2}$ Nathalie Richa ${ }^{2}$

To cite: Avedissian T, Honein-AbouHaidar G, Dumit N, et al. Anaphylaxis management: a survey of school and day care nurses in Lebanon. BMJ Paediatrics Open 2018;2:e000260. doi:10.1136/ bmjpo-2018-000260

- Additional material is published online only. To view please visit the journal online (http://dx.doi.org/10.1136/ bmjpo-2018-000260).

TA and GH-AH contributed equally.

Received 1 February 2018 Accepted 30 May 2018 Revised 25 May 2018

\section{ABSTRACT}

Objective Children are at a high risk of developing allergic reactions. Since they spend lots of time at the school or day care, the odds of having an allergic event in this setting is high, hence placing the onus of properly managing their event on nurses. In Lebanon, little is known whether a standardised policy for managing allergic and anaphylactic reaction exists, leaving children unsafe and the school personnel liable. Thus, the aim of this study is to describe the current practices in the management of severe allergies and anaphylaxis by Lebanese nurses working in schools and day cares and to explore the perceived need for a protocol to manage anaphylaxis reaction.

Methods A cross-sectional survey with nurses working at schools and day cares in Lebanon was conducted.

Results A total of 59 school and day care nurses participated. Eighteen of the school and day care nurses reported having a written policy describing the management steps. Only 12 had witnessed an anaphylactic event. Of those, 10 reported administering an antihistamine medication orally instead of epinephrine intramuscular. Most respondents (56) believed that a standardised guideline for the management of anaphylaxis was essential, and 9 indicated being hesitant to give the epinephrine intramuscular even in the presence of a policy. Finally, 55 stated the need for training nurses in identifying and managing anaphylaxis as a must.

Conclusion Currently, the management of anaphylaxis reaction in schools and day cares is suboptimal. Hence, there is a need for a standardised nursing guideline and training for nurses in these settings .

\section{BACKGROUND}

Allergic and anaphylactic reactions are on (C) Author(s) (or their employer(s)) 2018. Re-use permitted under CC BY-NC. No commercial re-use. See rights and permissions. Published by BMJ.

${ }^{1}$ Hariri School of Nursing, American University of Beirut, Beirut, Lebanon

${ }^{2}$ Order of Nurses in Lebanon, Beirut, Lebanon

\section{Correspondence to}

Tamar Avedissian, Hariri School of Nursing, American University of Beirut; ta18@aub.edu.lb, gh30@aub.edu.lb the rise worldwide. ${ }^{1-3}$ It is estimated that $0.05 \%-2 \%$ of the worldwide population develop at least one episode of allergic reaction in their lifetime. ${ }^{1}$ Several factors can be attributed to this rise, including intensified exposure to environmental pollutants, better reporting and increased awareness. ${ }^{24}$ Some allergic reactions may lead to anaphylaxis and may be fatal. ${ }^{15}$ Anaphylaxis defined as 'a serious, life-threatening generalised or systemic hypersensitivity reaction', ${ }^{46}$ often happens in the community without the presence of a healthcare provider. ${ }^{17}$ When managed properly, survival rates are high,

\section{What is already known on this topic?}

- Anaphylaxis events are on the rise worldwide.

- Best treatment option is epinephrine intramuscularly (IM).

- International standards advocate the school nurses stock epinephrine and administer it IM during an emergency.

\section{What this study hopes to add?}

In Lebanon, school and day care nurses do not have a standardised policy in anaphylaxis management and they are administering antihistamines orally.

- These nurses are calling for a policy development that allows them to administer epinephrine having a physician's order and parental consent.

- Training of these nurses, parents and the involved stakeholders is important.

with a case fatality ratio of $<1 \%$; otherwise it can lead to sudden death. ${ }^{8}$ Therefore, proper and timely management is crucial for survival. ${ }^{4}$ For this reason, community training is essential, especially for healthcare workers, to recognise the early signs of anaphylactic reactions and take prompt actions. ${ }^{9}$

Given that children spend a great deal of their time at the school or the day care, the odds of having an allergic and anaphylactic reaction iis high. In fact, about 16\%-18\% of students with food allergies developed an allergic reaction at school. ${ }^{10-12}$ This places the school nurse at the front line to face and manage such a fatal reaction. Consequently, school nurses need to have a unified, comprehensive guideline for the management of anaphylaxis. ${ }^{11}$ The treatment of choice for anaphylaxis is epinephrine intramuscular (IM).$^{1-471314}$ There is sufficient evidence that postponing epinephrine IM administration is related to greater chances of morbidity and mortality. ${ }^{1571415}$ Alternatively, antihistamines can be used, but they are known to take 1-3 hours to produce an effect, as compared with $\leq 10 \mathrm{~min}$ with epinephrine. The international standards support having a policy that 
allows school nurses to have epinephrine doses available, ${ }^{10}{ }^{15}$ with physician-standing orders to administer during a life-threatening anaphylactic event. ${ }^{16-18}$ Based on these recommendations, many countries developed anaphylaxis guidelines to protect susceptible students. ${ }^{11}$

This study was conducted in Lebanon, a country of 6.3 million including Syrian and Palestinian refugees. ${ }^{19}$ Children under 15 years of age make 26\% (1.64 million) of the population with approximately $90 \%$ being enrolled in schools. There are four types of schools: public, private, private for free, United Nations Relief and Works Agency for Palestine Refugees (UNRWA). Fifty-four per cent of students attend private schools while $29 \%$ attend public schools. School distribution varies by geographic region: $8 \%$ in Beirut, $11 \%$ in Mount Lebanon, $14 \%$ in Beqaa, 19\% in South, 24\% in North and 24\% in Beirut Suburbs. Out of the 1282 public schools and the 1077 private schools not mentioning the day cares, there are only 126 nurses who are working at these settings. ${ }^{20}$

The significance of allergy and anaphylaxis problem has been reported in a few studies in Lebanon. A study conducted at an institutional level reported that $82 \%$ of patients had generalised allergic reactions, with $18 \%$ fitting the criteria for anaphylaxis. About half of the time $(52 \%)$, the causative agent was not known and the standard treatments for anaphylaxis were antihistamines as well as corticosteroids in hospitals ${ }^{21}$ similar to practices reported in other countries. ${ }^{15}$ Irani and Maalouly reported on the prevalence of food allergy nationwide and found that the prevalence was $4.1 \%$ in infants and children and $3.2 \%$ in adults, and signs of anaphylaxis appeared in $10.8 \%$ of cases. ${ }^{22}$ In another study, sesame seed reactions were severe and anaphylaxis was the only clinical manifestation. ${ }^{23}$ As for death due to anaphylaxis, we could not locate any figure partly because of inadequacies in documentation of the death certificates. ${ }^{24}$

In Lebanon, there is no clear policy for the management of anaphylaxis. Thus, at-risk children in these settings remain vulnerable and nurses' interventions unstandardised. This practice gap was a major concern for the Order of Nurses in Lebanon (ONL). Thus, this study was conducted in collaboration with the ONL and included all school health nurses registered at the Order, hence a national nursing survey. It was conducted with the intention of answering the following research questions: (1) what are the current practices in the management of anaphylaxis reaction by Lebanese nurses working in private schools and day cares; (2) is there a perceived need for a better management of anaphylaxis reactions; (3) does previous encounter with anaphylaxis and having written standard orders influence the perceived need for better management?

\section{METHODS}

Design

This study used a cross-sectional survey design targeting all nurses working at schools and day cares across
Lebanon. The approval of the American University of Beirut Institutional Review Board was secured before data collection. To avoid any undue influence, the consent form included a statement to inform participants that their participation is voluntary and will not affect their relationship with ONL.

\section{Population}

We used the database of registered nurses ( $\mathrm{RN})$ available at ONL, which initially included 164 nurses. ${ }^{25}$ The completeness and accuracy of these data was not validated. But given that this was the most reliable source, we used it to identify the eligible RNs. Following distribution of the survey, we found that 35 nurses had left their workplace and 3 nurses were unreachable, leaving 126 nurses working in schools and day cares. Given the small population size, we targeted them all.

\section{Instrument}

The survey instrument was adapted from a study done by Cicutto $e t a l,{ }^{11}$ whose permission was safeguarded before its adoption (online supplementary appendix 1: survey instrument). The questionnaire consisted of four sections allowing participants to add their comments after each question: (1) presence of a guideline for the management of anaphylaxis at schools; (2) current practices; (3) perceptions on whether a better management guideline is needed as well acceptance of administering epinephrine IM; and (4) demographic questions about gender, age, nursing specialty, years of practice, type of school and geographic area of school. The survey questions were translated into Arabic and back translated into English; both the original and back translated English versions demonstrated semantic equivalence. Before administering the survey, the questions were pilot tested with three school or day care nurses for relevance, clarity of items and ease of administration. Accordingly, minor modifications were made and these nurses were not included in the analysis.

\section{Data collection}

Data collection comprised two consecutive correspondences and took place from mid-April to May 2017. At first, the consent form along with the survey instrument was mailed in a sealed envelope. The nurses who agreed to participate and completed the survey were then asked to contact the research team to collect the surveys from them. After 3 weeks from sending the mail, a follow-up phone call was made to those who did not participate.

\section{Statistical analyses}

Data were entered into and analysed using IBM_SPSS Statistics V.24.0 for Windows. All variables were summarised using descriptive statistics. Bivariate analyses were conducted to test the association between independent, mediating and outcome variables using $\mathrm{X}^{2}$ and Fisher exact test for small cell size. Participants' additional comments were analysed qualitatively using descriptive content analysis approach. 


\section{RESULTS}

\section{Study population characteristics}

The response rate was about $47 \% \quad(n=59)$. The majority (56) of the participants were women. Forty nurses were working in private schools, 14 were in private daycares and 5 were in a private school that had a day care section. None of the respondents were employed at the public, private for free or UNRWA schools. Moreover, most of them (34) were from the Mount Lebanon region, some (13) from Beirut the capital and the remaining 12 were from the Northern, Bekaa or Southern regions. Thirty-four reported being 31-40 years old and 46 nurses hadd a Bachelor of Science degree in nursing. About 25 nurses had 6-10 years of previous clinical experience and $23 \mathrm{had}$ 6-10 years of experience at a school or day care. Moreover, 35 participants stated being the sole nurse responsible for the health of all students and staff, and 33 of them were accountable for $>700$ children.

\section{Current policies, processes and training sessions}

As shown in table 1, everyone stated having medical records which included previous allergic or anaphylactic history. Interestingly 34 nurses had a policy that intended to prevent an incident of anaphylaxis, but only 18 of them had a written policy describing the management steps. Moreover, only eight participants stated having epinephrine vials for intramuscular use and six had the Epi-pen autoinjector. Also, 15 nurses pointed out having a prescription from the child's own physician rather than a standard written order of epinephrine. Additional comments revealed that generally managing an anaphylactic reaction included transferring the child to a nearby hospital (online supplementary appendix 2).

Concerning training, only 11 reported training their staff in identifying an anaphylactic episode and 4 in administering the Epi-pen autoinjector. Additional comments revealed that most of the time staff were advised to refer the student to the RN (table 1: current policies, processes and training for the management of anaphylaxis reaction at the school/day care and online supplementary appendix 2.

\section{Previous experience in the management of anaphylaxis reaction}

Out of the 12 RNs who reported encountering anaphylactic reactions only 1 administered epinephrine IM as the first line treatment, the remaining gave an oral antihistamine and 9 nurses called the parents to transfer the child to the hospital (table 2: previous experience in the management of anaphylaxis reaction at the school/ day care). Fifty-six nurses perceived that a standardised guideline for the management of anaphylaxis was essential. Moreover, 47 considered having epinephrine IM available in these settings indispensable, but preferred having a written standing order from a physician along with parental consent. However, nine nurses reported being hesitant to administer an epinephrine IM injection even with such modifications. Nearly 55 of
Table 1 Current policies, processes and training for the management of anaphylaxis reaction at the school/day care $(n=59)$

\begin{tabular}{lcc}
\hline Variable & Frequency & Percent* \\
\hline $\begin{array}{l}\text { Have a policy for anaphylaxis } \\
\text { prevention by avoiding confirmed } \\
\text { allergens (eg, banning peanuts) }\end{array}$ & & \\
$\quad$ No & 24 & 41 \\
Yes & 34 & 59
\end{tabular}

Have a written policy for managing

life-threatening allergies protocol

$\begin{array}{lcc}\text { No } & 38 & 68 \\ \text { Yes } & 18 & 32 \\ \begin{array}{l}\text { Have medical records that specify } \\ \text { children who have an allergy }\end{array} & & \\ \quad \text { Yes } & 59 & 100 \\ \begin{array}{l}\text { Have epinephrine or epinephrine } \\ \text { ampoules available for } \\ \text { intramuscular use during an } \\ \text { emergency event }\end{array} & & \\ \quad \text { No } & 51 & 86 \\ \text { Yes } & 8 & 14\end{array}$

Have Epi-pen autoinjectors

available for emergency use

\begin{tabular}{lrc} 
No & 53 & 90 \\
Yes & 6 & 10 \\
$\begin{array}{l}\text { Have written standard orders of } \\
\text { epinephrine injection for emergency } \\
\text { usage }\end{array}$ & \\
No & 43 & \\
Yes & 15 & 74 \\
\hline
\end{tabular}

The staff are trained to administer

Epi-pen autoinjector if available

$\begin{array}{lrr}\text { No } & 55 & 93 \\ \text { Yes } & 4 & 7 \\ \begin{array}{l}\text { School/day care awareness and } \\ \text { training sessions are provided by }\end{array} & \\ \begin{array}{l}\text { healthcare providers (physicians } \\ \text { or nurses) to identify and manage } \\ \text { anaphylaxis }\end{array} & \\ \quad \text { No } & 48 & \\ \text { Yes } & 11 & 81\end{array}$

Have encountered a case of

anaphylaxis reaction

\begin{tabular}{llc} 
No & 44 & 79 \\
Yes & 12 & 21 \\
\hline
\end{tabular}

*Valid percent is used accounting for missing data.

the participants agreed on the need to educate nurses in properly diagnosing and managing anaphylaxis, but a few added considering the nurse's educational preparation as an element for that (online supplementary appendix 2). 
Table 2 Previous experience in the management of anaphylaxis reaction at the school/day care $(n=12)$

\begin{tabular}{lcc}
\hline Variable & Frequency & Percent $^{*}$ \\
\hline $\begin{array}{l}\text { Have administered Epinephrine } \\
\text { (Epinephrine) IM as first treatment }\end{array}$ & & \\
option for anaphylaxis & 11 & 92 \\
$\quad$ No & 1 & 8 \\
Yes & &
\end{tabular}

Have administered antihistamine medications IM as first treatment option

\begin{tabular}{|c|c|c|}
\hline No & 10 & 83 \\
\hline Yes & 2 & 17 \\
\hline \multicolumn{3}{|c|}{$\begin{array}{l}\text { Have administered antihistamine } \\
\text { medications orally as first treatment } \\
\text { option }\end{array}$} \\
\hline No & 2 & 17 \\
\hline Yes & 10 & 83 \\
\hline \multicolumn{3}{|c|}{ Have administered oxygen therapy } \\
\hline No & 10 & 83 \\
\hline Yes & 2 & 17 \\
\hline \multicolumn{3}{|c|}{$\begin{array}{l}\text { Called the ambulance to take the } \\
\text { child/student/staff to the emergency } \\
\text { department }\end{array}$} \\
\hline No & 7 & 58 \\
\hline Yes & 5 & 42 \\
\hline
\end{tabular}

Called the parents or the guardian to take the student/child/staff to the emergency department

\begin{tabular}{lll} 
No & 2 & 18 \\
\multicolumn{1}{c}{ Yes } & 9 & 82 \\
$\begin{array}{l}\text { The nurse accompanied the } \\
\text { student/child/staff to the emergency } \\
\text { department }\end{array}$ & \\
No & 5 & 42 \\
Yes & 7 & 58 \\
\hline
\end{tabular}

A staff member took the case to the emergency department

\begin{tabular}{lll} 
No & 9 & 75 \\
Yes & 3 & 25 \\
\hline
\end{tabular}

*Valid percent is used accounting for missing data.

\section{DISCUSSION}

The results of this study show the strong perceived need for better management of anaphylaxis in Lebanese schools and daycares. Although few (12) reported actually witnessing and managing a case of anaphylaxis as is the case in the literature, ${ }^{5}$ but the stakes remain high. Poor management may still lead to adverse outcomes, leaving both children and nurses in an unsafe state.

Epinephrine as the favoured first-line treatment is not always available. Even in its presence, only one participant used it, while the majority relied on oral antihistamines.
This practice is congruent with the literature, ${ }^{5}$ but oral antihistamines take more time to be effective, and result in partial treatment. Our empirical evidence suggests that it is imperative to have policy changes, stocks of epinephrine available, training for nurses and staff plus a standardised approach for managing anaphylaxis. In a retrospective study, Feuille et al revealed that as a consequence of training and policy change, there was better reporting and a triple increase in appropriate use of epinephrine. $^{26}$

Evidence is scarce and shows suboptimal management of anaphylaxis in the region as well. A study conducted by Mohammed Elhassan et al revealed that in Qatar, communicating children's allergic and anaphylactic reactions by parents to schools occurred in $23 \%$ of cases only and $84 \%$ of school personnel reported being unable to recognise symptoms of anaphylaxis. Comparable to our study, only $6 \%$ of school personnel used epinephrine. ${ }^{27}$ Hence, there is an urgent need for improvement in anaphylaxis management and increase in knowledge among caregivers as well as families in Lebanon and the region.

\section{Strengths and limitations}

Our study is the first to explore the state of anaphylaxis management in Lebanese schools and day cares. Despite the small sample size, we were able to target all the RNs working in schools and day cares. However, there are several limitations to be noted, most importantly in Lebanon, many daycares and schools, especially the public governmental ones, do not have an RN on site. Even our non-responders were employed at private schools or day cares according to the ONL registry. Hence, little is known about the management of anaphylaxis in these schools and future studies need to target that by gathering information from teachers, school administrations, students and parents. For these situations, the literature suggests providing comprehensive training sessions to non-health care personnel. ${ }^{28}$ Furthermore, this study is a self-reported survey with some missing data, due to the fact that participants were free to omit questions. Measures to address missing data were not needed since very few of them were skipped. Moreover, self-reported data are associated with recall bias and social desirability bias. However, our results are still comparable to regional and international studies therefore, it remains important enough to lead to the development of a guideline as well as training programmes. Another limitation is we were not able to collect data from non-respondents to examine whether there is a non-response bias due to ethical board considerations. However, we believe that this would not change the outcomes of this study. Finally, this study did not address important issues that would complete the circle of appropriate management of anaphylaxis including the communication between families and schools and between schools and primary care providers which can be addressed in the future. ${ }^{27}$ 


\section{Implications}

It is important for schools and day cares to have a clear plan of action delineated as an emergency response to anaphylaxis in order to create a safe environment for children. ${ }^{16}$ Having a standardised guideline needs to be based on evidence. ${ }^{1}$ This study provided empirical evidence for the need for improvement in the management of anaphylaxis reactions at schools in Lebanon. Hence, our next step is to develop a task force that will be responsible for developing guideline. It would be prudent to include other stakeholders such as allergy and immunology physicians, school administrators as well as parents to ensure better compliance. ${ }^{20}$ Given that our main collaborator is ONL, the body responsible for regulating the role of nurses in the country, our logical next step is to collaborate with them in addition to all the other stakeholders like the Ministries of Public Health and Education, Society of Paediatricians, school administrations, parents and teachers, to draft a policy for anaphylaxis management. Once drafted, a dissemination strategy to raise awareness and most importantly adherence needs to be implemented.

Practice implications need to follow the development of guidelines. The majority (47) believed that having epinephrine in these settings was essential, but 51 did not have it. This used to be the case in other countries; ${ }^{16}$ however by placing legislations, Australia, Canada and the USA mandated their schools to have epinephrine on site. ${ }^{11}$ Lebanese school and day care nurses in turn need to modify their practice by stocking epinephrine for IM use in line with the new proposed guidelines. ${ }^{16}$ It is also important to train nurses about the changes in practice guidelines. Although 33 assumed being confident in administering epinephrine IM, yet some remained hesitant, as is the case in the literature signifying the need for training and education. ${ }^{1}$ In order to promote safe nursing practice and administration of the correct treatment, having a readily standing physician orders for epinephrine IM use will enhance compliance. Further, children and family education is necessary to inform about the new guidelines and proper follow-up in order to reduce future recurrences. ${ }^{26}$

Implementation research study is needed to introduce the anaphylaxis policy in all schools especially those without school health nurses in order to identify facilitators, barriers and appropriate measures for applying and adhering to the new practice guideline. Moreover, our results indicate that $100 \%$ of the nurses self-reported having medical records for their students. What is needed is a database capturing all students with allergies, attack episodes, management approaches and patient outcomes. Finally, once a policy has been introduced a time series analysis is needed to test the impact of this policy on reporting prevalence of anaphylaxis and management.

\section{CONCLUSION}

The findings of the study reveal a suboptimal standardised guideline in the management of anaphylaxis within these settings. Since the literature states the presence of a guideline is effective in saving lives ${ }^{18}$ this calls for policy and practice change in the anaphylaxis management by the nurses. Even though in our study the nurses cover partially the student population in the country, yet when they are present, they are held accountable for the health outcomes. Consequently, it is still important to have a standardised guideline, with stocks of epinephrine available taking into account the physician's oversight in order to secure an order. Training nurses and other designated personnel is necessary to help in proper identifying and intervening on due course.

Acknowledgements The authors would like to thank the nurses who participated in the study. They also would like to acknowledge Ellen Buckner, PhD, for her contributions and critical feedback of early drafts. They thank the Order of Nurses in Lebanon for supporting the study as well as the staff for support and contributions, especially Aline Mrad.

Contributors TA and GH-A: study design, data acquisition, analysis and interpretation; writing of the manuscript. ND and NR: data acquisition and manuscript reviewing. All authors reviewed and approved the final draft.

Funding This study was supported by the Order of Nurses in Lebanon. Competing interests None declared.

Ethics approval This study was approved by the Institutional Review Board of the American University of Beirut.

Provenance and peer review Not commissioned; externally peer reviewed.

Open access This is an open access article distributed in accordance with the Creative Commons Attribution Non Commercial (CC BY-NC 4.0) license, which permits others to distribute, remix, adapt, build upon this work non-commercially, and license their derivative works on different terms, provided the original work is properly cited, appropriate credit is given, any changes made indicated, and the use is non-commercial. See: http://creativecommons.org/licenses/by-nc/4.0/.

\section{REFERENCES}

1. Wagner CW. Anaphylaxis in the pediatric patient: optimizing management and prevention. Journal of Pediatric Health Care 2013;27:S5-17.

2. Bryant $\mathrm{H}$. Anaphylaxis: recognition, treatment and education. Emerg Nurse 2007;15:24-8.

3. Simons FE, Ardusso LR, Bilò MB, et al. International consensus on (ICON) anaphylaxis. World Allergy Organ J 2014;7:1-19.

4. Jevon P. Recognition and treatment of anaphylaxis in the community. Br J Community Nurs 2010;15:449-53.

5. Worm M, Eckermann O, Dölle S, et al. Triggers and treatment of anaphylaxis: an analysis of 4,000 cases from Germany, Austria and Switzerland. Dtsch Arztebl Int 2014;111:367-75.

6. Armstrong N, Wolff R, van Mastrigt $\mathrm{G}$, et al. A systematic review and cost-effectiveness analysis of specialist services and adrenaline auto-injectors in anaphylaxis. Health Technol Assess 2013;17:1-117.

7. Jacobsen RC, Toy S, Bonham AJ, et al. Anaphylaxis knowledge among paramedics: results of a national survey. Prehosp Emerg Care 2012;16:527-34.

8. Younker J, Soar J. Recognition and treatment of anaphylaxis. Nurs Crit Care 2010;15:94-8.

9. Walker S, Chantrell J, Clarke S, et al. Primary care training for adults and children with confirmed anaphylaxis requiring treatment with adrenaline. Primary Health Care 2010;20:33-40.

10. Young MC, Muñoz-Furlong A, Sicherer SH. Management of food allergies in schools: a perspective for allergists. J Allergy Clin Immunol 2009;124:175-82.

11. Cicutto L, Julien B, Li NY, et al. Comparing school environments with and without legislation for the prevention and management of anaphylaxis. Allergy 2012;67:131-7. 
12. Polloni L, Baldi I, Lazzarotto F, et al. School personnel's self-efficacy in managing food allergy and anaphylaxis. Pediatr Allergy Immunol 2016;27:356-60.

13. Bethel J. Anaphylaxis: diagnosis and treatment. Nurs Stand 2013;27:49-56.

14. Hogue SL, Goss D, Hollis K, et al. Training and administration of epinephrine auto-injectors for anaphylaxis treatment in US schools: results from the EpiPen4Schools(®) pilot survey. J Asthma Allergy 2016;9:109-15.

15. Fineman SM. Optimal treatment of anaphylaxis: antihistamines versus epinephrine. Postgrad Med 2014;126:73-81.

16. Zadikoff EH, Whyte SA, Desantiago-Cardenas L, et al. The development and implementation of the Chicago public schools emergency EpiPen $\AA$ policy. J Sch Health 2014;84:342-7.

17. Gregory NL. The case for stock epinephrine in schools. NASN Sch Nurse 2012;27:222-5

18. Muraro A, Roberts G, Worm M, et al. Anaphylaxis: guidelines from the European Academy of Allergy and Clinical Immunology. Allergy 2014;69:1026-45.

19. El-Jardali F, Fadlallha R, Matar L. Primary health care systems (PRIMASYS): case study from Lebanon: WHO, 2017.

20. BANKMED. Analysis of lebanon's education sector. 2014. https:// www.bankmed.com.lb/BOMedia/subservices/categories/News/ 20150515170635891.pdf
21. Hitti EA, Zaitoun F, Harmouche $\mathrm{E}$, et al. Acute allergic reactions in the emergency department: characteristics and management practices. Eur J Emerg Med 2015;22:253-9.

22. Irani C, Maalouly G. Prevalence of self-reported food allergy in lebanon: a middle-eastern taste. Int Sch Res Notices 2015;2015:1-5.

23. Irani C, Maalouly G, Germanos M, et al. Food allergy in Lebanon: is sesame seed the "middle eastern" peanut. World Allergy Organ J 2011;4:1-3.

24. Sibai AM, Nuwayhid I, Beydoun M, et al. Inadequacies of death certification in Beirut: who is responsible? Bull World Health Organ 2002;80:555-61.

25. Anon. Order of nurses in Lebanon statistics. 2015 http://www. orderofnurses.org.lb/ (accessed on 29 Aug 2016).

26. Feuille $\mathrm{E}$, Lawrence $\mathrm{C}$, Volel $\mathrm{C}$, et al. Time trends in food allergy diagnoses, epinephrine orders, and epinephrine administrations in New York City schools. J Pediatr 2017;190:93-9.

27. Mohammed Elhassan S, Charlson M, Jama H, et al. Management of anaphylaxis in children: a survey of parents and school personnel in Qatar. BMJ Paediatr Open 2017:1:1.

28. Polloni L, Lazzarotto F, Toniolo A, et al. What do school personnel know, think and feel about food allergies? Clin Transl Allergy 2013;3:39. 